\title{
Magnitude of Diabetic Foot Ulcer and Associated Factors among Diabetic Patients Who Attended Diabetic Follow-up Clinics in Gamo and Gofa Zones, Southern Ethiopia

\author{
Asegid Regas $^{1 *}$, Befikadu Tariku², Esekezaw Agedew ${ }^{2}$ and Busera Seman ${ }^{3}$
}

${ }^{1}$ Wonsho Woreda Health Office, Sidama Region, Ethiopia

${ }^{2}$ Department of Public Health, College of Medicine and Health Sciences, Arba Minch University, Arba Minch, Ethiopia

${ }^{3}$ Hawassa College of Health Sciences, Hawassa, Ethiopia

*Corresponding author: Mr. Asegid Regas Tabour, Wonsho Woreda Health Office, Sidama Region, Ethiopia, E-mail: asegidregas79@gmail.com, Tell: +251916075079/+251973670567

\begin{abstract}
Background: The most common and devastating complication of diabetes mellitus that affect the lower extremities among people with diabetes is a diabetic feet ulcer. Diabetic foot ulcer increases develop multiple risk factors like foot infections, prolonged healing time, poor quality of life, gangrene, and lower limb non-traumatic amputations. Worldwide, the incidence and magnitude of diabetic foot ulcer rapidly increase since the diabetes disease dramatically increased and it reached an epidemic level. However, there is limited evidence on the occurrence of foot ulcer and influencing factors in Ethiopia, particularly in the study area.
\end{abstract}

Objective: The aim of this study was to assess the magnitude and associated factors of diabetic foot ulcer among diabetic patients who attended the diabetic follow-up clinics at Gamo and Gofa zones, Southern Ethiopia.

Methods: A health facility-based cross-sectional study was conducted in public hospitals found in Gamo and Gofa zones, Ethiopia. Simple random sampling was used to select 325 study participants. All patients diagnosed with diabetic mellitus were included in the study. Data was collected by six trained data collectors using pre-tested interviewer administered questionnaires. Physical examination and patient medical record was reviewed. Data was checked, cleaned, coded and entered into EPI-INFO version 7 and then exported to SPSS for analysis. Binary logistic regression analysis was performed to identify independent factors associated with a diabetic foot ulcer and statistical significance was declared at $p$-value $<0.05$. Multivariable logistic regression analysis was made to estimate the independent effect of predictors on the occurrence of diabetic foot ulcer.
Result: The magnitude of diabetic foot ulcer was $15.5 \%$ [95\% Cl: 11.94-19.83]. In final multivariable logistic regression model, being male $[A O R=3.04 \mathrm{p}: 0.038]$, presence of peripheral neuropathy $[A O R=4.48, p: 0.001]$, vision impairment $[A O R=2.90, p: 0.04]$, duration of diabetic mellitus illness $[A O R=1.91, p: 0.034]$, deformity $[A O R=9.1$, : $0.001]$, sensory lost to vibration [AOR $=3.89, \mathrm{p}: 0.003$ ], foot pedal pulse $[A O R=3.74, p: 0.004]$, glycemic control [AOR $=4.16, \mathrm{p}: 0.01]$, ill-fitting shoe $[\mathrm{AOR}=2.6, \mathrm{p}: 0.03]$ and foot self-care practice [AOR $=3.42, p: 0.017]$ were found to have a negative significant association with diabetic foot ulcer.

Conclusion: The study showed a high magnitude of diabetic foot ulcer among people with diabetes attending diabetic follow-up clinics at Gamo and Gofa zones. The presence of peripheral neuropathy, sensory loss to vibration, absence of pedal pulse, foot deformity, and poor glycemic control, visional impairment, duration of diabetic mellitus, use of ill-fitting shoe and foot self-care practice was significantly associated with the development of diabetic foot ulcer.

\section{Keywords}

Diabetes, Foot ulcer, Ethiopia

\section{Background}

Diabetes mellitus is a chronic disease, which results from either failure of insulin production/insufficient production or resistance for its action on peripheral tissues [1]. It is mainly characterized by hyperglycemia. Persistence hyperglycemia condition has toxics effect on body systems, which leads to peripheral neuropathy, peripheral vascular disease, increased risk of in-

Citation: Regas A, Tariku B, Agedew E, Seman B (2021) Magnitude of Diabetic Foot Ulcer and Associated Factors among Diabetic Patients Who Attended Diabetic Follow-up Clinics in Gamo and Gofa Zones, Southern Ethiopia. Int J Diabetes Clin Res 8:139. doi.org/10.23937/2377-3634/1410139

Accepted: May 01, 2021: Published: May 03, 2021

Copyright: (c) 2021 Regas A, et al. This is an open-access article distributed under the terms of the Creative Commons Attribution License, which permits unrestricted use, distribution, and reproduction in any medium, provided the original author and source are credited. 
fection and poor wound healing [2].

Diabetes is a serious health problem that needs special attention in the twenty-first century. According to International Diabetic Federation [3], it is estimated that $\mathbf{4 2 5}$ million people living with this condition globally and this number would be projected to 642 million in 2040 . Indeed, nearly $80 \%$ of people with diabetic live in low and middle-income countries [3].

The most common and devastating complication affecting the low extremities among people with diabetes are diabetic foot ulcer. It is defined as any ulceration, necrosis, gangrene, or full thickness skin defect occurring distal to the ankle in a diabetic patient [4]. Diabetic foot ulcer occurred on $15 \%$ of patients with diabetes during their lifespan [5]. Approximately more than half of the recent onset of diabetic foot ulcer became infected. Twenty percent of the infected foot ended up amputated $[6,7]$.

Most of the non-traumatic low extremities amputated in relation to people with diabetes are preceded by a diabetic foot ulcer $[8,9]$. The probability to develop diabetic foot ulcer on the second leg increased by half within 2 years among. In addition, the recurrence of diabetic foot ulcer is higher within five years [10].

Amputations can lead to long-term changes in patients' mobility, living conditions and relationships. They can substantially reduce the quality of life. People with diabetes who had amputated are also at risk of premature death $[11,12]$.

In the sub-Saharan African countries, diabetic foot ulcer was a frequently unfocused health problem. Particular; there is limited evidence on the occurrence of foot ulcer and influencing factors in Ethiopia. This stu$d y$ is, therefore, aimed to assess the magnitude and associated factors of diabetic foot ulcer among diabetic patients who attended the diabetic follow-up clinics at Gamo and Gofa zones, Southern Ethiopia. The output of this study will complement the available prevention strategies targeted at reducing the occurrence of diabetic foot ulcer and its complications.

\section{Methods and Materials}

\section{Study design and settings}

Institutional based cross-sectional study design was conducted in diabetic follow-up clinics at Gamo and Gofa Zone, Southern Ethiopia from January to April 2018. Gamo and Gofa zones are among the zones found in Southern Nations, Nationalities, and Peoples Region. Its administrative center, Arba Minch town, is located 505 KM South West of Addis Ababa. In the zones, there are 7 government hospitals, 21 urban health centers, 52 rural health centers and 471 health posts. Among these health facilities, only three hospitals have diabetic follow-up clinic.

\section{Study population}

All patients aged above or equal to 18 years that were diagnosed with diabetes mellitus, and who attended the diabetic follow-up clinic in Gamo and Gofa zone hospitals during the study period was included in the study. People with diabetes who had traumatic ulcer and those who were severely ill and unable to communicate throughout the study period were excluded from the study.

\section{Sample size and sampling procedure}

Sample size was determined by using a single population proportion formula by considering the following assumptions: The proportion of diabetic foot ulcer among people with diabetes whose age $>=18$ in Tikur Anbessa Specialized Hospital, Ethiopia (TASH) was $26 \%$ [13]. The precision $5 \% ; 95 \%(Z \alpha / 2=1.96)$ confidence interval and $10 \%$ for non-response. Accordingly, the total sample size was 325 . Computer-generated simple random sampling technique was used to select the study participants from each hospital. First, diabetic patient care number/registration numbers sorted and used to generate the random numbers. Then, considering these lists as a sampling frame, study participants were selected randomly. The sample size was allocated proportionally based on the previous year's number of diabetic patients at each hospital diabetic follow-up clinics.

\section{Operational Definitions}

\section{Diabetes}

Were diagnosed if the patients with a fasting plasma glucose level $=>126 \mathrm{mg} / \mathrm{dl}$ or $2 \mathrm{hr}$ post-glucose level after a 75 -g oral glucose tolerance test $=>200 \mathrm{mg} / \mathrm{dl}$ plus suggestive clinical manifestations.

\section{Diabetic foot ulcer}

Non-traumatic a (partial or full thickness) skin break from the distal to the malleoli in a person who has diabetes mellitus [14].

\section{Severity of diabetic foot ulcer classification}

Based on Wagner's Classification. Grade zero (intact skin), grade 1 (superficial ulcer), grade 2 (deep ulcer to tendon, bone, or joint), grade 3 (deep ulcer with abscess or osteomyelitis), grade 4 (forefoot gangrene), and grade 5 (whole foot gangrene) [15].

\section{Ill-fitting foot wear}

Were defined as the presence of one or more of the following too tight, or too wide, high heel, poor quality or hard leather, or soft insole for patients with DM [16].

\section{Diabetic foot self-care practice}

There are 12 questions which were be used to assess diabetic foot self-care practice of the patients. Based on the response of the study participants' response, 
"mean" were be used as a cutoff point to determine above mean level it has "Good foot self care practice" and below mean level as "poor foot self-care practice".

\section{Controlled diabetes mellitus}

If the three consecutive fasting blood glucose level was between $70-130 \mathrm{mg} / \mathrm{dl}$, it was considered "controlled and above $130 \mathrm{mg} / \mathrm{dl}$ uncontrolled or (Good control Or poor control) based [17].

\section{Peripheral vascular disease}

Palpate the posterior tibial artery and dorsalis pedis artery in both feet and record pulsations as absent or present 2/4 [18].

\section{Neuropathy (painful neuropathy)}

It were diagnosed if the patient had at least one manifestation from the following list of manifestations: Describe sharp, stabbing, burning, shooting or electric shock type pain, which may be worse at night and can disrupt sleep [18].

\section{Peripheral sensory neuropathy}

The absence of Vibration perception by Tuning fork $128 \mathrm{~Hz}$ in feet (both left and right feet) [19].

\section{Inappropriate foot wear}

The shoes that have not appropriate with the shape and size of shoe with foot.

\section{Follow up regularly}

Missing three subsequent visits on follow up diabetes clinics.

\section{Data Collection and Quality Control}

A Pretested questionnaire was used to collect dates on socio-demographic, clinical and behavioral factors. A Checklist was used to extract data from medical records. A physical examination was performed for each patient to determine peripheral vascular disease and severity of ulcer based on Wagner Ulcer Classification. Weight and height of study participants was measured using standard procedures. Data was collected by six trained BSc nurses and supervised by three health officers who had previous experience of data collections. The collected data was checked for completeness, accuracy, and consistency each day by the investigators.

\section{Data Analysis}

Data was entered using EPI-INFO version 7 and transferred to SPSS version 23 for analysis. Descriptive statistical analysis was performed for variables such as socio-demographic characteristics of clinical factors, behavioral factor, and foot self-care practice. A both bivariate and multivariable logistic regression was performed to identify factors associated with the outcome variable. Variables having $p$-value $\leq 0.25$ in the bivariate analyses was fitted into multivariable logistic regression models to control the effects of confounding. A crude and adjusted odds ratio with their $95 \% \mathrm{Cl}$ was estimated to determine the strength of association. A p-value less than 0.05 in the multivariable analysis was considered to declare statistical significance $[20,21]$.

\section{Ethical Consideration}

An ethical clearance was obtained from Institutional Ethical Review Board of Arba Minch University. Written Permission was secured from each medical director of three hospitals in the Gamo and Gofa zone. The purpose of the study was briefly explained to concerned offices, and people with diabetes who visited the clinics. People with Diabetes were asked for their willingness to participate in the study and informing them they could withdraw at any time, for any reason. The data collection process started after oral consent was obtained from respective bodies. Confidentiality was maintained throughout the study by using code number.

\section{Result}

\section{Socio-demographic characteristics of study subjects}

Three hundred and twenty three individuals who had diabetic follow-up in three hospitals in Gamo and Gofa zone was involved in the study with the response rate of $99.38 \%$. From total respondents, 205 (63.5\%) were males. The mean (SD) age of participants was $50.71( \pm$ $13.93)$ years. Nearly half $(n=156)$ of the respondents was Orthodox Christians by religion and 268 (83\%) was married. About one in five $(22.9 \%)$ of the respondents was farmers (Table 1 ).

\section{Clinical characteristics of the study participants}

One hundred and eighty six $(60.7 \%)$ of the respondents diagnosed with diabetes mellitus less than five years ago. The mean (SD) of fasting blood glucose level among diabetic patients was 159.3 (53.9) $\mathrm{mg} / \mathrm{dl}$. The mean systolic and diastolic blood pressure level was 120.6 (12.9) and 77.1 (12.5), respectively. The majority of the study participants $(73 \%)$ had type two diabetes mellitus. Nearly $18 \%$ of the respondents had not had a regular follow up practice and $33 \%$ of the respondents did not taken their medication at regular intervals. Two hundred and fifty-three (78.3\%) had poor glycemic control. Thirty-two percent of the respondents have had one or more symptoms of the peripheral neuropathic disorder (Table 2).

\section{Behavioral factors of the study participants}

Seventeen (5\%) of respondents was smokers of tobacco products at the time of data collection. Regarding alcohol consummation, 90 (27.9\%) of the respondent ever used alcohol and 85 (26.3\%) of them used alcohol in the past 30 days. The median time spends in physical activities among diabetic individual was 1440 MET-min/ week. 
Table 1: Socio-demographic characteristics of the study participants in Gamo and Gofa, SNNPR, Ethiopia, March to April $2018(n=323)$.

\begin{tabular}{|c|c|c|c|}
\hline Characteristics & Categories & $\mathbf{N}$ & $\%$ \\
\hline \multirow[b]{2}{*}{ Sex } & Female & 118 & 36.5 \\
\hline & Male & 205 & 63.5 \\
\hline \multirow[t]{5}{*}{ Age } & $18-27$ & 19 & 5.9 \\
\hline & $28-37$ & 39 & 12.5 \\
\hline & $38-47$ & 63 & 19.5 \\
\hline & $48-57$ & 80 & 24.8 \\
\hline & $>58$ & 122 & 37.8 \\
\hline \multirow{6}{*}{$\begin{array}{l}\text { Educational } \\
\text { status }\end{array}$} & Can't read and write & 118 & 36.5 \\
\hline & Reading and writing & 38 & 11.8 \\
\hline & Primary education & 32 & 9.9 \\
\hline & $\begin{array}{l}\text { Secondary } \\
\text { education }\end{array}$ & 45 & 13.9 \\
\hline & Diploma & 57 & 17.6 \\
\hline & Degree & 33 & 10.2 \\
\hline \multirow{5}{*}{ Marital status } & Never married & 21 & 6.5 \\
\hline & Currently married & 270 & 83.6 \\
\hline & Widowed & 24 & 7.4 \\
\hline & Divorced & 7 & 2.2 \\
\hline & Separate & 1 & 0.3 \\
\hline \multirow{5}{*}{ Religion } & Catholic & 4 & 1.2 \\
\hline & Muslim & 24 & 7.4 \\
\hline & Orthodox & 156 & 48.3 \\
\hline & Other & 1 & 0.3 \\
\hline & Protestant & 138 & 42.7 \\
\hline \multirow{9}{*}{ Occupation } & Farmer & 74 & 22.9 \\
\hline & Government & 71 & 22.0 \\
\hline & Housewife & 72 & 22.3 \\
\hline & Merchant & 60 & 18.6 \\
\hline & Non-government & 2 & 0.6 \\
\hline & Retired & 21 & 6.5 \\
\hline & Student & 14 & 4.3 \\
\hline & Unemployed & 7 & 2.2 \\
\hline & Weaver & 2 & 0.6 \\
\hline
\end{tabular}

\section{Foot self-care practice of the study participants}

One hundred and thirty seven (42.2\%) Study participants did not inspected or monitors their foot health on a daily basis and 227 (70.3\%) Respondents did not used skin softeners products. Two hundred and eleven (63.3\%) they do not cut their toes short or appropriately. A significant number of the respondents (39\%) ever walked on barefoot outside of the home and/or filed. Nearly half of the respondents (52.3\%) did not wear special shoes recommended by the physician. More than half of the respondents (55\%) never check any injuries in the foot and 123 (38.1\%) of the respondents was use ill-fitting shoes.
Table 2: Clinical and diabetic information of the study participants in Gamo and Gofa zones, SNNPR, Ethiopia March-April, $2018(n=323)$.

\begin{tabular}{|c|c|c|c|}
\hline Characteristics & Categories & $\mathbf{N}$ & $\%$ \\
\hline \multirow{3}{*}{ Time of diagnosed } & $<5$ years & 196 & 60.7 \\
\hline & $5-10$ & 89 & 27.6 \\
\hline & Above 10 years & 38 & 11.8 \\
\hline \multirow{2}{*}{ Type of diabetes } & T1DM & 87 & 26.9 \\
\hline & T2DM & 236 & 73.1 \\
\hline \multirow{3}{*}{$\begin{array}{l}\text { Diabetic medication } \\
\text { currently }\end{array}$} & $\begin{array}{l}\text { Oral } \\
\text { hypoglycemic }\end{array}$ & 188 & 58.2 \\
\hline & Insulin & 119 & 36.8 \\
\hline & Mixed & 16 & 5 \\
\hline \multirow{2}{*}{ Follow up regularly } & Yes & 266 & 82.4 \\
\hline & No & 57 & 17.6 \\
\hline \multirow{2}{*}{$\begin{array}{l}\text { Fasting blood glucose } \\
\text { Average }\end{array}$} & Good control & 70 & 21.7 \\
\hline & Poor control & 253 & 78.3 \\
\hline \multirow{2}{*}{$\begin{array}{l}\text { Peripheral neuropathic } \\
\text { disorder ( }>=1 \text { symptom) }\end{array}$} & Yes & 104 & 32.2 \\
\hline & No & 219 & 67.8 \\
\hline \multirow{2}{*}{ Vision Impairment } & Yes & 51 & 15.8 \\
\hline & No & 272 & 71.5 \\
\hline \multirow{2}{*}{ History of foot ulcer } & Yes & 24 & 7.4 \\
\hline & No & 299 & 92.6 \\
\hline \multirow{2}{*}{ Deformity on foot } & Yes & 44 & 13.6 \\
\hline & No & 279 & 86.4 \\
\hline \multirow{2}{*}{ Foot pulses } & Present & 243 & 75.2 \\
\hline & Absent & 80 & 24.8 \\
\hline \multirow{2}{*}{$\begin{array}{l}\text { Sensory loss to vibration } \\
(128 \mathrm{~Hz})\end{array}$} & Yes & 111 & 34.4 \\
\hline & No & 212 & 65.6 \\
\hline \multirow{2}{*}{ Callus on foot } & Present & 117 & 36.2 \\
\hline & Absent & 206 & 63.8 \\
\hline \multirow{2}{*}{ Foot wear } & Appropriate & 258 & 79.9 \\
\hline & Inappropriate & 65 & 20.1 \\
\hline
\end{tabular}

\section{The magnitude of diabetic foot ulcer among study participants}

The magnitude of diabetic foot ulcer was $15.5 \%$ [95\% Cl: 11.9-19.9]. Based on Wagner's classification of severity of ulcer, $92 \%$ of the diabetic foot ulcer patients were classified as grade 0 and four presents was grade one and grade two receptively.

\section{Factors associated with the development of dia- betic foot ulcer}

In final multiple logistic regression analysis results show that, being male was three $(A O R=3.0,95 \% \mathrm{Cl}$ : 1.06-8.71) time more likely to develop diabetic foot ulcer. Diabetes duration of above ten years was two time more likely to develop diabetic foot ulcer. Sensory loss to vibration by $128 \mathrm{~Hz}$ was 3.9 times more likely develop the outcome status. People with Diabetes those who have the symptom of PND four times to develop diabetic foot ulcer. A People who diabetes those who had de- 
Table 3: Bivariat and Multivariable analysis of factors associated with diabetic foot ulcer in Gamo and Gofa Zone, SNNPR 'Ethiopia April-March, $2018(\mathrm{n}=323)$.

\begin{tabular}{|c|c|c|c|c|c|c|}
\hline \multirow{2}{*}{ Variable } & \multirow{2}{*}{ Category } & \multicolumn{2}{|l|}{ DFU } & \multirow{2}{*}{ COR $(95 \% \mathrm{Cl})$} & \multirow{2}{*}{ AOR $(95 \% \mathrm{Cl})$} & \multirow{2}{*}{ p-value } \\
\hline & & Yes (\%) & No (\%) & & & \\
\hline \multirow{2}{*}{ Sex } & Male & $40(80)$ & $165(60.4)$ & $2.61(1.28-5.45)^{\star *}$ & $3.04(1.06-8.71)$ & \multirow{2}{*}{0.038} \\
\hline & Female & $10(20)$ & $108(39.6)$ & 1 & 1 & \\
\hline \multirow{2}{*}{ Area of residence } & Rural & $33(66)$ & $103(37.7)$ & $3.20(1.69-6.04)^{* \star *}$ & & \\
\hline & Urban & $17(34)$ & $170(62.3)$ & 1 & & \\
\hline \multirow{3}{*}{ Educational status } & Can't read and write & $33(66)$ & $85(31.1)$ & $4.65(2.32-9.32)^{*+* *}$ & & \\
\hline & Read and write & $4(6)$ & $32(11.7)$ & $1.5(0.45-4.89)^{\star \star \star}$ & & \\
\hline & Formal Education & $13(26)$ & $156(57.1)$ & 1 & & \\
\hline \multirow{2}{*}{$\begin{array}{l}\text { Peripheral } \\
\text { Neuropathic } \\
\text { disease }\end{array}$} & Yes & $30(60)$ & $72(26.4)$ & $4.96(2.62-9.38)^{* * *}$ & $4.48(1.81-11.08)$ & \multirow[b]{2}{*}{0.001} \\
\hline & No & $20(40)$ & $201(73.5)$ & 1 & 1 & \\
\hline \multirow{2}{*}{$\begin{array}{l}\text { Visional } \\
\text { Impairment }\end{array}$} & Yes & $31(62)$ & $66(24.2)$ & $5.60(2.82-11.20)^{* * *}$ & $2.90(1.05-8.01)$ & \multirow{2}{*}{0.04} \\
\hline & No & 19 [20] & $207(75.8)$ & 1 & 1 & \\
\hline \multirow{2}{*}{$\begin{array}{l}\text { Foot self care } \\
\text { practice }\end{array}$} & $\begin{array}{l}\text { Poor self care } \\
\text { practice }\end{array}$ & $42(84)$ & $146(53.5)$ & $0.21(0.99-0.48)$ & $3.42(1.25-9.37)$ & \multirow{2}{*}{0.017} \\
\hline & $\begin{array}{l}\text { Good self care } \\
\text { practice }\end{array}$ & $8[10]$ & $127(46.5)$ & 1 & 1 & \\
\hline \multirow{2}{*}{ Type of DM } & T2DM & $40[21]$ & $196(71.8)$ & $1.57(0.74-3.29)$ & & \\
\hline & T1DM & $10(20)$ & $77(28.2)$ & 1 & & \\
\hline \multirow{3}{*}{ Duration of DM } & Above 10 years & $15(30)$ & $23(8.4)$ & $7.8(3.4-18.17)^{\star * *}$ & $1.91(1.05-3.49)$ & 0.034 \\
\hline & $5-10$ years & $20(40)$ & $69(25.3)$ & $3.49(1.69-7.2)^{\star \star}$ & & \\
\hline & $<5$ years & $15(30)$ & $181(66.3)$ & 1 & 1 & \\
\hline \multirow{2}{*}{ Foot pulse } & No (Absent) & $26(54)$ & $54(22.7)$ & $4.39(2.34-8.24)^{* *}$ & $3.74(1.52-9.20)$ & \multirow{2}{*}{0.004} \\
\hline & Yes (present) & 24 [20] & $219(80.2)$ & 1 & 1 & \\
\hline \multirow{2}{*}{ III fitting shoe } & Yes & $25(50)$ & $97(35.5)$ & $1.81(0.88-3.33)$ & $2.6(1.07-6.42)$ & \multirow{2}{*}{0.035} \\
\hline & No & 25 & $176(64.5)$ & 1 & & \\
\hline \multirow{2}{*}{ Follow up regular } & No & $12(24)$ & $45(16.5)$ & $1.6(0.77-3.29)$ & & \\
\hline & Yes & $38(76)$ & $228(83.5)$ & 1 & & \\
\hline \multirow{2}{*}{ Deformity } & Present & $33(66)$ & $78(28.6)$ & $8.69(4.24-17.79)^{* * * *}$ & $9.1(3.4-24.3)$ & \multirow{2}{*}{0.001} \\
\hline & Absent & $17(34)$ & $195(71.4)$ & 1 & 1 & \\
\hline Sensory lost to & Yes & $30(60)$ & $81(16.5)$ & $3.55(1.9-6.62)^{\star * *}$ & $3.89(1.61-9.38)$ & 0003 \\
\hline vibration & No & $20(40)$ & 192 (70.) & 1 & 1 & 0.003 \\
\hline & Yes & 24 [20] & $76(27.8)$ & $2.39(1.29-4.42)^{* *}$ & & \\
\hline Callus of the toot & No & $26(52)$ & $197(72.2)$ & 1 & & \\
\hline BMI (Overweight/ & BMI $\left(>=25 \mathrm{~kg} / \mathrm{m}^{2}\right)$ & $36(72)$ & $148(54.2)$ & $0.46(0.23-0.89)$ & & \\
\hline obesity) & $\mathrm{BMI}\left(<25 \mathrm{~kg} / \mathrm{m}^{2}\right)$ & $14[20]$ & $125(45.8)$ & 1 & & \\
\hline & Poor control & $42(84)$ & $155(56.8)$ & $5.09(1.53-16.9)^{\star *}$ & $4.16(1.4-12.3)$ & \\
\hline Glycemic control & Good control & 8 [10] & $118(43.2)$ & 1 & 1 & 0.010 \\
\hline Skin texture & Dry and crack & $34(32)$ & $86(31.5)$ & $4.62(2.4-8.8)^{\star \star *}$ & & \\
\hline Skın texture & Smooth and moist & $16(32)$ & $187(68.5)$ & 1 & & \\
\hline Physical & $<600 \mathrm{MET}$ & $12(24)$ & $70(25.6)$ & $0.57(0.28-1.15)$ & & \\
\hline activities(MET & 600-2999 MET & $20(40)$ & $134(49.1)$ & $0.65(0.29-1.46)$ & & \\
\hline $\min / \mathrm{wk}$ & $>=3000 \mathrm{MET}$ & $18[10]$ & $69(25.3)$ & 1 & & \\
\hline
\end{tabular}

[Note: ${ }^{*}=$ p-values $<0.05,{ }^{* *}=$ P-value $<0.01,{ }^{* * *}=$ P-value $\left.<0.001\right]$.

formity was significant association of DFU and Absence of pedal pulse, visual Impairment poor glycemic control, wear ill-fitting shoe also associated with diabetic foot ulcer. A people who diabetes who had good Foot self-care practice also associated with DFU. In contrast to this, $\mathrm{BMI}$, skin texture, callus of foot was not significantly associated with DFU in final model. 


\section{Discussion}

Diabetic foot ulcer is one of the most common and devastating complication of diabetes mellitus. Unless the disease untreated and uncontrolled an eventually the disease will result complete loss vascularity and death of tissue. The consequence of the disease not only affect health also impact on social, psychological and financial crisis. So herein has the important identified the risk factors in the development of foot ulcer and its curial element for the prevention mechanism.

The magnitude of diabetic foot ulcer in our study is $15.5 \%$ [95\% Cl: 20-24]. Which is comparably with studies was conducted Gondar and Arbaminch Ethiopia, the prevalence was 13.6 and $14.8 \%$ respectively $[22,23]$. The result was considerably higher than the studies reported on different countries, its ranges from 3.4\%$8.7 \%$ [24-30]. This variation is may be due to knowledge related diabetic foot self-care practice, knowledge on disease and also possibly due to disparity on health-seeking behavior and quality of lives among the study population. The current finding was a bit lower than the studies reported from black lion specialized hospital in Ethiopia and Khartoum and Sudan was $18.1 \%$ and $26 \%$ respectively $[13,31]$. This could be attributed by difference in the sample size and year of survey and also socio-demographic factors:- majority of the respondents in this study was came from rural area and operational definition.

Severity of DFU, $61 \%$ of diabetic foot ulcer were in Wagner's grade 0 , grade 1,2 and 3 were $46(36 \%), 0.6 \%$ and $0.6 \%$ respectively. This is in line with the studies done in black line specialized hospital Ethiopia, grade one was $31.1 \%$, two, three and four was $(6.1 \%, 12.2 \%$ and $16.3 \%$ ) respectively [32]. The study that was done in Jordan show that Grade 0, 1, 2 and 3 (7.3\%, 3.4\%, 0.9\% and $0.3 \%$ ) respectively [33].

Males more commonly allied on the development foot ulcer but a few studies were not appreciating these relations $[34,35]$. However in this study the magnitude of diabetic foot ulcer higher on males, which account $80 \%$ and for females $20 \%$. This find in line with the studies done in Jamaica (for male $22.2 \%$ and for female $4.2 \%$ ) and Jordan (for male group 6.3\% and for female group $2.6 \%)[25,33]$. And consistent with the studies done in different areas $[25,28,33,36]$. However, the result of this study was in contrast with finding of case control study in Malaysia (26.6\% for males and $43.8 \%$ for females) [37]. This is might be due to Male were spent more time in farm area working their job in bare foot that make exposed to injury, additionally males mostly involved in risk activities that make exposed them to injury. On other hand; Skin softener commonly was not using by male rather it used by female. Any situation female was using these products. This has been taking as cultural habit in mostly community of our country. According to this study significant number of males 160
(70.5\%) were not use skin softener when compared to female 67 (29.5\%). The diabetes impact progress more its affect the skin that become dry that can make individual to rub his/her skin that may lead to skin break that consequence formation of diabetic foot ulcer [38].

The finding of this study illustrate that duration of diabetes, above Ten years 1.9 time more likely to develop diabetic foot ulcer compare to duration less than five years (AOR 1.91, 1.05, 3.49, $p=0.03$ ). This finding in line the studies was conducted in Egypt, Sudan South west of Iran $[24,38,39,40,41]$ and also Indonesia [24,39,41, 42]. The reason might be, Longer someone with had diabetes mellitus might exposed hyperglycemic condition in his life span and this cumulative glycemic burden had toxic consequence might affect all part of the body including skin and foot. Longstanding hyperglycemia causes a reaction between the glucose and collagen leading to the resultant formation of Advanced Glycation End products (AGE) [43]. The depositions of these AGE's into the Achilles tendon, capsules and ligaments of the foot, creates collagen toughness and inelasticity causing stiffness and rigidity in the foot. This causes limited joint mobility which results in an inability of the foot to function with its two main goals to adapt to terrain and to distribute pressure and there is a relationship between high peak plantar pressures and limited joint mobility.

In the current study, it was found that sensory lost to vibration was a significant risk factor for diabetic foot ulcer. Four time fold as develop of diabetic foot ulcer. (1.61-9.38, $p=0.003)$ This was consistent with studies was conducted Jordan, Gondar-Ethiopia and Cameroon $[23,27,30]$. This might be attributed to the fact that patients with sensory lost to vibration leads to loss of protective function and deficits of recognition even the broken glass, burn and repetitive trauma.

In the current study those who have the symptom of Peripheral neuropathy disease 4.48 time more likely to develop diabetic foot ulcer compared to those who lack of peripheral neuropathy disorder (AOR 4.48; 1.81$11.08 p=0.001)$. This study is in line with the studies was done in Gondar, Ethiopia and Jordan $[23,44]$. Regarding to having Impaired Vision were 2.8 times more likely develop diabetic foot ulcer than those who did not have impaired vision $[A O R=2.8 ; 95 \% \mathrm{Cl} ; 1.31,6.37)$. This find is in line with the study conducted in Ghana [23]. This might be, daily inspection and self-assessment of the foot are one of the earliest identification of a risk and key mechanism of prevention of the development of diabetic foot ulcer. However, the patient with impaired vision often deficit the ability of successfully observes and identifies any abnormality in their foot that lead and exacerbate the occurrence of diabetic foot ulcer.

In the current study, it was found that diabetic foot self-care practice were significant for the prevention of diabetic foot ulcer. Those diabetic patient who had poor foot self-care practice were 3.6 times more likely 
to develop diabetic foot ulcer than those diabetic patients who had Good foot self-care practice [AOR 3.6; $95 \% \mathrm{Cl} 1.60,8.19)$. The finding of the present study is comparable to studies conducted in Gonder North West, Ethiopia [23] Dares Salaam, Tanzania; Nairobi and Sudan $[31,45,46]$. Indeed practice are the mirror image of activate that carry out in daily life. But deficit of daily inspection of the foot, washing and drying between the toe, keeping skin as to as smooth and moist, appropriate wearing of shoes and health seeking behavior may influencing factors of the development of diabetic foot ulcer.

According to this study, having foot deformity 3 times more likely to be develop diabetic foot ulcer when compared to those diabetic patients who had not deformity[AOR $=3 ; 95 \% \mathrm{Cl} 1.48,6.52]$. This finding was also in line with studies was conducted in Egypt, Nepal, Sri Lanka and Thailand showed that direct relationship between deformity and foot ulcer $[24,47]$. This could be related with in less developing country in including Ethiopia shoes manufacture industry were not consider those who had foot deformity individual. That make diabetic patient enforced to wear the normal shoes that available in market for non-diabetic individual. The abnormal architecture of the foot bone especial prominence part of the foot that faced repetitive stress that forms callus formation that result the development of ulceration on the foot.

In the present study shows that poor glycemic controlled were a significant risk factor for development of diabetic foot ulcer. Those who had poor glycemic control 4.16 time more likely develop diabetic foot ulcer than compared to good glycemic control (AOR 4.16; $95 \% \mathrm{Cl}, 1.4-12.3)$. Similar findings were reported North West Gondar, Ethiopia; Kenya Nairobi and Amman, Jordan $[23,24,44,48]$. The fact that nearly half of respondents $(45 \%)$ had implies that there is poor control of blood sugar. It might be poor glycemic control may exposed to persistent hyperglycemic that lead influence all body system including skin that make ulcer formation. Good Control of blood glucose requires a combination of using correct dose of medication, being adherent to treatment and carefully controlling calorie intake and physical activity. However contract the cross sectional study glycemic control were not significant factors for the development of diabetic foot ulcer [24]. Also the current study shows that use of ill-fitting shoes as risk factors of the development of diabetic foot ulcer which were in line with study carry out in Arba Minch, Ethiopia [48]. This it might due to repetitive pressure on the prominence party of foot may forms callus that may increase the chance of development of diabetic foot ulcer and also high chance and frequency of foot injury.

\section{Conclusion}

The study showed higher magnitude of diabetic foot ulcer among diabetic patients attending health facilities in Gamo and Gofa zones; when compared with referenced literature. Begin male gender, presence of peripheral neuropaths, sensory lost to vibration, absence of pedal pulse, foot deformity, poor glycemic control, visional Impairment, duration of diabetic mellitus illness, use of ill-fitting shoe and foot self-care practice were significant associated with the development of diabetic foot ulcer. Diabetic care providers should struggle to reduce the occurrence of the unwanted diabetic complication like diabetic foot ulcer, neuropathy disorder and peripheral vascular disease by providing health education and by awareness creation about the impact of diabetes on their own health. Further community based and prospective follow-up studies will be beneficial to identify the clear incidence and prevalence of diabetic foot ulcer and to determine the potential risk factor of diabetic foot ulcer.

\section{Limitation of the Study}

Despite filling a gap in the literature in Ethiopia, our study was some limitations.

- There might be recall bias or reporting bias regarding the contributing factors, such as alcohol use or exercise frequency. Further, the cross-sectional nature of the study does not confirm the definitive cause and effect relation.

- Peripheral arterial disease was defined based on the absent pedal pulsation which was assessed by palpation. But IWGD recommended measurement of the ankle brachial pressure indexes it will better (ABPI).

- To check neuropathy it was recommended $10 \mathrm{~g}$ monofilament with one of the four clinical tests mandatory to increased sensitivity and specific of the measurement tools but on current market monofilament was not available. So I use only 128 $\mathrm{Hz}$ tuning fork to assess Neuropathy (sensory lost to vibration).

\section{Conflicts of Interest}

We declare that we have no conflict of interests.

\section{Acknowledgements}

We would like to pass our gratitude to Arbaminch University for funding this research. We are very grateful to all data collectors, supervisors and study participants for their cooperation and assistance.

\section{References}

1. Markakis K, Bowling F, Boulton A (2016) The diabetic foot in 2015: An overview. Diabetes Metab Res Rev. 32: 169178.

2. Belgium B (2015) Diabetes Atlas. International Diabetes Federation.

3. Schaper N, Andros G, Apelqvist J, Bakker K, Lammer J, et al. (2012) Specific guidelines for the diagnosis and treatment of peripheral arterial disease in a patient with diabe- 
tes and ulceration of the foot 2011. Diabetes Metab Res 2 : 236-237.

4. Songer T (2001) The role of cost effectiveness analysis and health insurance in diabetes care. Diabetes Res Clin Pract 54: S7-S11.

5. Prompers L, Huijberts M, Apelqvist J, Jude E, Piaggesi A, et al. (2007) High prevalence of ischaemia, infection and serious comorbidity in patients with diabetic foot disease in Europe. Baseline results from the Eurodiale study. Diabetologia 50: 18-25

6. (2017) Chapter 21: Neuromuscular disorders. Dartmouth. edu.

7. Carmona G, Hoffmeyer P, Herrmann F, Vaucher J, Tschopp O, et al. (2005) Major lower limb amputations in the elderly observed over ten years: The role of diabetes and peripheral arterial disease. Diabetes Metab 31: 449-454.

8. Thorud JC, Plemmons B, Buckley CJ, Shibuya N, Jupiter DC (2016) Mortality after nontraumatic major amputation among patients with diabetes and peripheral vascular disease: A systematic review. J Foot Ankle Surg 55: 591-599.

9. Udeet E (2001) Assessment of the diabetic foot. In: Chronic Wound Care. (3rd edn), HMP Communications Inc.

10. Yusuf S, Okuwa M, Irwan M, Rassa S, Laitung B, et al (2016) Prevalence and risk factor of diabetic foot ulcers in a regional hospital, Eastern Indonesia. Journal of Nursing, 6 .

11. Vamos E, Bottle A, Majeed A, Millett C (2010) Trends in lower extremity amputations in people with and without diabetes in England, 1996-2005. Diabetes Res Clin Pract 87: 275-282.

12. Singh D (2006) Diabetic foot: It is time to share the burden. Calicut Med J 4: e4.

13. Yimam A (2017) Assessment of magnitude of diabetic foot ulcer and associated factors among diabetic patientattending tikur anbesa specialized hospitaldiabetic clinic, Addis ababa, Ethiopia.

14. NICE (2015) Diabetic foot problems: Prevention and management.

15. Wagner FW (1981) The dysvascular foot: A system of diagnosis and treatment. Foot Ankle 2: 64-122.

16. Williams A (2007) Footwear assessment and management: Understanding shoe construction and materials aids in properly fitting patients. Podiatry Management.

17. America Diabetes Association: Tight glucose control.

18. Armstrong D, Tobin C, Matangi M (2010) The accuracy of the physical examination for the detection of lower extremity peripheral arterial disease. Can J Cardiol 26: e346-e350.

19. Vijay V, Snehalatha C, Seena R, Ramachandran A (2001) The rydel seiffer tuning fork: An inexpensive device for screening diabetic patients with high-risk foot. Pract Diabetes Int 18: 155-156.

20. Kumhar M, Saini T, Dara N (2014) Foot wear and footcare knowledge-an independent risk factor for diabetic foot in Indian diabetics. Indian Medical Gazette 148: 25-28.

21. Merkin S, Diez Roux A, Coresh J, Fried L, Jackson S, et al. (2007) Individual and neighborhood socioeconomic status and progressive chronic disease in an elderly population: The Cardiovascular Health Study. Soc Sci Med 65: 809-821.

22. Bedilu D, Kifle W, Gugsa N (2014) Prevalence and factors influencing diabetic foot ulcer among diabetic patients attending arbaminch hospital, South Ethiopia. JDM 5: 1.
23. Mariam TG, Alemayehu A, Tesfaye E, Mequannt W, Temesgen K, et al. (2017) Prevalence of diabetic foot ulcer and associated factors among adult diabetic patients who attend the diabetic follow-up clinic at the University of Gondar Referral Hospital, North West Ethiopia, 2016: Institutional-Based Cross-Sectional Study 2017: 2879249.

24. Sarinnapakorn V, Sunthorntepwarakul T, Deerochanawong C, Niramitmahapanya S, Napartivaumnuay N (2016) Prevalence of diabetic foot ulcers and risk classifications in type 2 diabetes mellitus patients at Rajavithi Hospital. J Med Assoc Thai 99: S99-S105.

25. Ferguson TS, Tulloch-Reid MK, Younger NO, Wright-Pascoe RA, Boyne MS, et al. (2013) Diabetic foot complications among patients attending a specialist diabetes clinic in Jamaica: Prevalence and associated factors. West Indian Med J 62: 216-223

26. Nyamu PN, Otieno CF, Amayo EO, McLigeyo SO (2003) Risk factors and prevalence of diabetic foot ulcers at Kenyatta National Hospital, Nairobi. East Afr Med J 80: 3643.

27. AlAyed MY, Younes N, Al-Smady M, Khader YS, Robert AA, et al. (2017) Prevalence of foot ulcers, foot at risk and associated risk factors among Jordanian Diabetics. Curr Diabetes Rev 13: 182-191.

28. Del Brutto $\mathrm{OH}$, Mera RM, King NR, Zambrano M, Sullivan LJ (2016) The burden of diabetes-related foot disorders in community-dwellers living in rural Ecuador: Results of the Atahualpa Project. Foot (Edinb) 28: 26-29.

29. Assaad-Khalil SH, Zaki A, Abdel Rehim A, Megallaa MH, Gaber N, et al. (2015) Prevalence of diabetic foot disorders and related risk factors among Egyptian subjects with diabetes. Primary Care Diabetes 9: 297-303.

30. Tindong $M$, Palle JN, Nebongo $D$, Aminde LN, MboueDjieka Y, et al. (2018) Prevalence, clinical presentation, and factors associated with diabetic foot ulcer in two regional hospitals in Cameroon. Int J Low Extrem Wounds 17: 42-47.

31. Balla SA, Ahmed HA, Alhassan SF (2013) Factors associated with diabetic septic foot among patients attending the diabetic septic foot unit in the Military Hospital, Khartoum State, Sudan. Saudi Journal of Medicine \& Medical Sciences 1: 98-102.

32. Amogne W, Reja A, Amare A (2011) Diabetic foot disease in Ethiopian patients: A hospital based study. Ethiopia J Health 25: 17-21.

33. Bakri GF, Allan AH, Khader YS, Younes NA, Ajlouni KM (2012) Prevalence of diabetic foot ulceration and associated risk factors among diabtic patients in jordan. $\mathrm{J}$ Med $\mathrm{J}$ 46: 118-125.

34. Jia L, Parker CN, Parker TJ, Kinnear EM, Derhy PH, et al. (2017) Incidence and risk factors for developing infection in patients presenting with uninfected diabetic foot ulcers. PLoS One 12: e0177916.

35. Nabil Abd El Fatah Al Kafrawy, Ehab Ahmed Abd El-Atty Mustafa, Alaa El-Din Abd El-Salam Dawood, Osama Mohammed Ebaid, Omnia Mahmoud Ahmed Zidane (2014) Study of risk factors of diabetic foot ulcers. Menoufia Med J 27: 28-34.

36. Qari FA, Akbar D (2000) Diabetic foot: Presentation and treatment. Saudi Med J 21: 443-446.

37. Misliza A, Ayu SM (2009) Sociodemographic and lifestyle factors as the risk of diabetic foot ulcer in the university of malaya medical centre. 12: 15-24. 
38. Quilici MTV, de Sá Del Fiol F, Vieira AEF, Toledo MI (2016) Risk factors for foot amputation in patients hospitalized for diabetic foot infection. J Diabetes Res 2016: 8931508.

39. Almobarak AO, Awadalla H, Osman M, Ahmed MH (2017) Prevalence of diabetic foot ulceration and associated risk factors: an old and still major public health problem in Khartoum, Sudan? Ann Transl Med 5: 340.

40. Yazdanpanah L, Shahbazian H, Nazari I, Arti HR, Ahmadi F, et al. (2018) Prevalence and related risk factors of diabetic foot ulcer in Ahvaz, south west of Iran. Diabetes Metab Syndr 12: 519-524.

41. O'Shea C, McClintock J, Lawrenson R (2017) The prevalence of diabetic foot disease in the Waikato region. Diabetes Res Clin Pract 129: 79-85.

42. Obaid HAA, Eljedi A (2015) Risk factors for the development of diabetic foot ulcers in gaza strip: A case-control study. International Journal of Diabetes Research 4: 1-6.

43. Newton V (2013) Key considerations for assessment and management of limited joint mobility in the diabetic foot. The Diabetic Foot Journal 16: 108-114.
44. Jbour AS, Jarrah NS, Radaideh ARM, Shegem NS, Bader IM, et al. (2003) Prevalence and predictors of diabetic foot syndrome in type 2 diabetes mellitus in Jordan. Saudi Med J 24: 761-764.

45. Atosona A (2017) Prevalence, risk factors and predictors of diabetes-related complications: Foot ulcers, lower extremity amputations and sexual dysfunction in three selected hospitals in Ghana. Kwame Nkrumah University of Science and Technology, 1-129.

46. Nongmaithem M, Bawa APS, Pithwa AK, Bhatia SK, Singh G, et al. (2016) A study of risk factors and foot care behavior among diabetics. J Family Med Prim Care 5: 399-403.

47. Deribe B, Woldemichael K, Nemera G (2014) Prevalence and factors influencing diabetic foot ulcer among diabetic patients attending Arbaminch Hospital, South Ethiopia. JDM, 5.

48. Cavanagh PS, Bus SA (2010) Off-loading the diabetic foot for ulcer prevention and healing. J Vasc Surg 52: 37S-43S. 